\title{
Improvement of assembly technique efficiency for installation of buildings and related structures in light building constructions
}

\author{
Anatoliy Drozdov ${ }^{*}$ \\ Moscow State University of Civil Engineering, Yaroslavskoe shosse, 26, Moscow, 129337, Russia
}

\begin{abstract}
Mounting technology from light steel structures gets evergrowing use in construction. The advantages of such technologies with their wide variety of applications are: durability, low specific gravity of structures, environmental friendliness, fire-resistance, low operation cost, fast efficient multi-season installation, resistance to stress, etc. Further development of this technology is associated with the improvement of normative base for calculation and design of buildings and related structures in light steel building constructions with indication of their loading and mounting parameters, implemented using riveting and screwed connections. Improving performance of erecting depends largely on the choice of a mechanized tool whereby these tasks are performed. Production processes of tightening screwed connections are carried out in vibroimpact modes, and one of the problems is to reduce vibration level decrease perceived by the operator, in order to protect him and extend the allowed operating hours. An effective method for solving it is employment of machinery with vibration control, with hydroimpulsive mechanisms in the drive.
\end{abstract}

\section{Introduction}

The development of the technology of bearing and enclosing structures of low-rise buildings predetermines the expansion of steel modules of various sizes in normative base for calculation and design of buildings and related structures in light steel building constructions with indication of their loading and mounting parameters, implemented using riveting and threaded joints $[1,2]$.

The purpose of this study is symbolic model formation of advanced types of screwdriving machines for manual hydroimpulsive nutrunners. They have vibration and noise control compared to traditional machines caused by the introduction of liquid rock oil layer to the contact metal-metal pair [3-8].

The present studies confirm the feasibility of the developed model in the calculations for such machines. With the accuracy of the results up to $15 \%$.[9-16]

Nutrunners with a hydroimpulsive mechanism - hydroimpulsive nutrunners - are perspective power tools. Primary virtues compared to impact machines include vibration

\footnotetext{
Corresponding author: lena-belkina8@yandex.ru
} 
and noise control, increased reliability of the design and stability of the developed tightening torque. In this study, a symbolic model is created, and an algorithm for optimizing machines of this class is proposed and implemented. The developed method can be used when selecting design values on the early design stage $[3,8,9]$.

\section{Models}

Fig. 1 shows a diagram of the hydroimpulsive mechanism of the blade type with four chambers. This scheme has simplicity, sufficient specific power, and also allows the generation of squared shape impact pulses, which carry the maximum amount of energy.

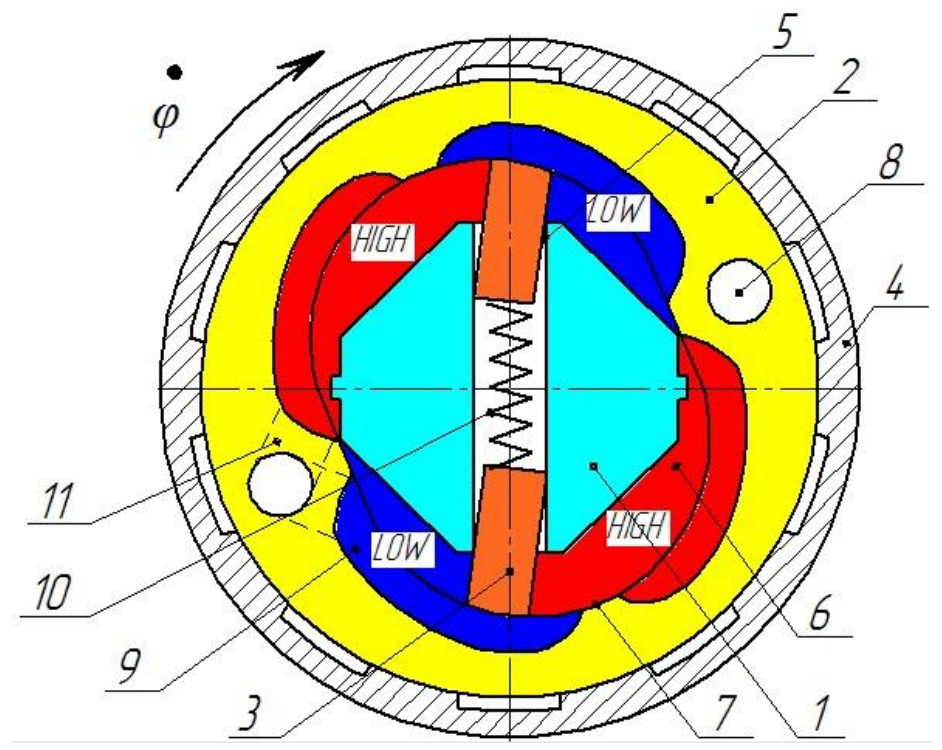

1 - spindle; 2 - body; 3 - blades; 4 - radiator holder; 5 - slots; 6 - working chamber; 7 - body's seal nose; 8 - bypass valve; 9 -ward; 10 - load spring; 11 - bypass valve passages.

Fig. 1. Scheme of the blade type four-chamber hydropimpulsive mechanism.

The impact head in this mechanism is the body 2 , connected to the actuating shaft. A spindle 1 is located inside the hollow striker. Blades 3 with springs 10 are inserted into spindle 1 slots. The hollow of a striker with an oval profile, the surface of which has semicircular wards 9, separated by four diametrically arranged noses 7. The enclosed volume of the body is oil-filled.

The procedure consists of a cycle of striker-body dispersal and a stroke cycle (dynamic seal). The spindle quarters the entire inside of the chamber (chambers 6 ). Running-up goes without obstacles, since these parts are connected by wards 9 and the channel under the spindle, thanks to which the liquid flows freely from one chamber to another. After making half rotation, the body of the chamber comes to the position about the spindle, in which body's seal noses 7, spindle noses and the blades are in an opposed relationship, overlapping the chambers connecting channels. The rate of change in the volume at this moment is maximum. The sealing of the gaps sends up liquid pressure in the high pressure chambers (HIGH) and causes de-aeration in the low pressure chambers (LOW). The kinetic energy of the striker is expended on squeezing-out flow action. Due to the pressure drop across the chamber parts and the presence of spindle large and small axes, angular momentum influences a striker and a spindle. The striker retards, spindle moment is 
transmitted to the tightened connection. The blade is tightened by the load springs 10 in the course of operation. A limiting device in this mechanism is the bypass ball valve 8 , which regulates the maximum pressure in the compression space.

\section{Methods}

Striking process mathematical model in given mechanism is the continuity equation, expressing that volume change in high-pressure chamber equals fluid flow from these chambers, caused by differential pressure, under fluid compressibility:

$$
\frac{d \Delta V_{B, D}}{d t}=Q+\frac{d \Delta V_{f c}}{d t}
$$

where $\Delta V_{f_{c}}$ - volume change due to fluid compressibility; $\Delta V_{B, D}$ - the law of variation of volume in high-pressure chambers; $Q$ - fluid flow through capillary openings.

Solution of the mathematical model for the dynamic seal with appropriate initial data in general terms is as follows:

$$
\Delta P_{B, D}(t)=\frac{B}{A}\left(1-e^{-A t}\right), \quad t \in\left[0 ; \frac{\varphi_{\text {seal }}}{\omega}\right]
$$

where $\Delta P_{B, D}-$ differential pressure in high-pressure chambers;

$$
A=\frac{4 \delta^{3} E}{6 \mu e^{b_{\mu} \Delta P_{B, D}} m K_{p}\left[a b \pi+2\left(b^{2}-a^{2}\right) \varphi_{\text {seall }}\right]}, B=-\frac{2 \omega E\left[K_{p}\left(b^{2}-a^{2}\right)+\delta(a-b)\right]}{K_{p}\left[a b \pi+2\left(b^{2}-a^{2}\right) \varphi_{\text {seall }}\right]}
$$

where $a, b-$ large and small semiaxes of body cavity;

$\mu-$ dynamic viscosity of oil;

$\delta$ - capillary thickness;

$\omega$ - angular velocity of the striker;

$\varphi_{\text {seal }}$ - angular size of seal noses;

$E$ - bulk modulus of fluid;

$m$ - capillary length;

$\varphi_{\text {seal-I }}$ - angular data on the beginning of the process in dynamic seal;

$K_{p}$ - packing factor of the body cavity with spindle components;

$b_{\mu}$ - multiplier that takes into account the dependence of viscosity on the pressure.

Taking into account the solution (2) of equation (1), the following relations of practical importance can be made:

1. Angular momentum:

$S_{M}=2(a-b) H \cos (90-\chi)\left(b-\frac{a-b}{2}\right) \frac{B}{A}\left[\frac{e^{-A \frac{\varphi_{\text {seal }}}{\omega}}}{A}\right]+\frac{\varphi_{\text {seal }}}{\omega}$,

where $\chi$ - blade angle

2. Striking energy:

$E_{s t}=\frac{S_{M}^{2}}{2 I_{s p}}$

where $I_{s p}$ - spindle inertia couple 
3. Striking Surge power:

$W_{s t}=E_{s t} n_{s t}=\frac{S_{M}^{2}}{2 I_{s p}} \frac{\omega}{\pi}$,

where $n_{s t}$ - number of strikes per time unit

Optimization of mechanism dynamic parameters (Fig. 1) should be carried out on the basis of energy-transfer by strike coefficient:

$$
\eta\left(x^{*}\right)=\max _{x \in X} \eta(x)
$$

where $\eta(x)$ - objective function;

$x=\left(a, b, H, \varphi_{\text {seal }}, \omega, \mu, E\right)^{T}-$ argument vector of objective function.

Acceptable solutions set $X \subset R^{7}$ is given by inequations:

$$
X=\left\{x \mid g_{j}(x) \leq 0, j=1, \ldots, k\right\},
$$

where $g_{j}(x)$ - constraint functions, $k$ - number of applied restrictions.

The constraint functions determine variation ranges of the dynamic and design values of the machine, as well as the specified impact energy.

Moreover, the objective function $\eta(\mathrm{x})$ is as follows:

$$
\eta=\left\{\begin{array}{lr}
\frac{S_{M}}{2 I_{s p} \omega} & I_{s p}>\frac{S_{M}}{2 \omega} \\
1 & I_{s p}=\frac{S_{M}}{2 \omega} \\
\frac{2 I_{s p} \omega}{S_{M}} & I_{s p}<\frac{S_{M}}{2 \omega}
\end{array}\right.
$$

\section{Conclusion}

Specialized software package was developed to optimize the hydropimpulsive nutrunner according to the proposed algorithm on the basis of which it was possible to synthesize a parametric series of machines with rational dynamic parameters in the energy range of a single strike of $0.8-3 \mathrm{~J}$. Application of these machines will boost the effectiveness of erection procedure technological effectiveness for structures concerned. 


\section{References}

1. J. Bródka, K., Milaczewski, R. Garncarek. Steel folded structures in construction, (1989)

2. I. A. Birger, G. B. Iosilevich. Threaded joints. Constructor's library. M.: Machinostroenie, (1973)

3. AtlasCopco. ErgoPulse PTS. [Online] http://www.atlascopco.com

4. DeWalt. DeWalt Compact SDS Rotary Hammers. DeWalt. [Online] (Citet: November 19, 2012) http://dewalt.com/tool-categories/hammerdrills--hammers-compact-sdsrotary-hammers.aspx.

5. Makita U.S.A., Inc. Rotary Hammers. Makita [Online] (Cited: November 19, 2012) http://makita.com/en-us/Modules/Tools/Default.aspx?CatID=45

6. Milwaukee Electric Tool Corporation. 5262-20 Operator's Manual. Brookfield: Milwaukee El. Tool Corpor, (2011)

7. Robert Bosch GmbH. Rotary Hammers. Bosch Power Tools. [Online] (Cited: November 19, 2012)

8. V. V. Stepanov. NTTM -2013: Official catalog of the XIII All-Russian Exhibition of Scientific-Technical Creativity of Youth, (2013)

9. Severugina N.S. Methods for estimating the perspective approximation of purchased means of mechanization of the organization of road construction. CRM, 47-50, 1 (2011).

10. A. N. Drozdov, V. V. Stepanov. Electric impact nutrunners. Dynamics: Monograph. M.: MSUCE, (2013)

11. A. N. Drozdov. J. "Advances in Intelligent Systems and Computing", publisher: Springer, 692 (2017)

12. A. N. Drozdov. The 4th Intern. Conf. on Advanced Engin. and Tech. (4th ICAET) (2017)

13. R. R. Sharapov. Bulletin of BSTU named after V. G. Shukhov, 1 (2011)

14. Ushakov L.S. Hydraulic shock mechanisms. World experience of calculation and design. Germany. Publ. house Palmarium Acad. Publ. 280 (2013).

15. V. V. Stepanov. Interstroimech-2013: Proc. of the Int. Inter. Res and Dev. Conf. Novocherkassk, (2013)

16. Chapra, Steven C. and Canale, P. Raymond. Numerical Methods for Engineers, 6th Ed. New York : McGraw-Hil. (2010) 